\title{
Substance use disorders and the orbitofrontal
}

\section{cortex}

\author{
Systematic review of behavioural decision-making \\ and neuroimaging studies
}

G. DOM, B. SABBE, W. HULSTIJN and W. VAN DEN BRINK

\section{Background Orbitofrontal cortex dysfunctions have been frequently documented in people with substance use disorders. The exact role of this cortical region, however, remains unspecified.}

Aims To assess the functionality of the orbitofrontal cortex in people with substance use disorders.

\begin{abstract}
Method Reports of studies using behavioural decision-making tasks and/or neuroimaging techniques to investigate orbitofrontal cortex functioning in cases of substance misuse were reviewed. Studies focusing exclusively on tobacco-smoking and gambling were excluded.
\end{abstract}

\begin{abstract}
Results Fifty-two research articles were evaluated. Most studies showed significant deficits in decision-making in people with substance use disorders. A consistent finding in the neuroimaging studies was hypoactivity of the orbitofrontal cortex after detoxification. The association between hyperactivity of this region and craving or cue reactivity was not consistent across studies.
\end{abstract}

Conclusions The orbitofrontal cortex has an important role in addictive behaviours. Further studies are needed to elucidate the underlying neuronal substrates of cue reactivity, craving and decision-making, and the implications for treatment and relapse prevention.

Declaration of interest None.
Traditionally, research into addictive processes and their treatment has focused on the mesolimbic dopaminergic reward system. Recently, however, interest in the potentially important role of the prefrontal cortex has increased; specifically, the orbitofrontal cortex is frequently implicated. This region is critically involved in inhibitory decision-making processes, especially in reward-related behaviours. It processes the reward value and/or affective valence of environmental stimuli, assesses the future consequences of the individual's own actions (response selection) and inhibits appropriate behaviours (response inhibition; Bechara \& Damasio, 2002; Krawczyk, 2002; Fan et al, 2003). Thus, the decision-making function of the orbitofrontal cortex is suggested to be closely related to the well-known addiction processes of craving, salience, continued drug use despite harmful consequences and relapse (Goldstein \& Volkow, 2002; Lubman et al, 2004). We explore the evidence supporting this hypothesis, integrating data from both behavioural decision-making and neuroimaging studies of participants with substance use disorders.

\section{METHOD}

We consulted the US National Library of Medicine (Medline) to identify studies conducted between January 1990 and May 2004. Only original research articles including study populations with substance use disorders were considered. Postmortem studies and studies focusing on tobacco-smoking or gambling only were excluded.

The keywords used to search the database were SUBSTANCE ABUSE or DEPENDENCE or DRUG ADDICTION, CRAVING or DRUG CRAVING, DECISION MAKING, NEUROIMAGING or FUNCTIONAL IMAGING, ORBITOFRONTAL CORTEX or
VENTROMEDIAL PREFRONTAL CORTEX, GAMBLING TASK or DECISIONMAKING TASK. Combinations of these search terms yielded 43 articles. Bibliographies were examined to identify further citations. Imaging studies were included if they used conservative statistical thresholding methods (e.g. corrections for multiple comparisons). Imaging studies in which the orbitofrontal cortex was not explicitly incorporated in the study design or in which the cue-presentation design might have been confounded by habituation effects (e.g. repetitive, longpresentation stimuli) were excluded. Three studies were excluded (Maas et al, 1998; Schneider et al, 2001; Wrase et al, 2002). Ultimately 52 studies were included in this review: 11 behavioural task studies and 41 neuroimaging studies.

\section{RESULTS}

Behavioural laboratory task studies

The main results of the studies using behavioural decision-making tasks are shown in Table 1. One study used the Rogers Cambridge Gamble Task (RCGT; Rogers et al, $1999 a$ ) and ten studies used the Iowa Gambling Task (IGT; Bechara et al, 1994). In the RCGT, participants make a simple probabilistic judgement between two mutually exclusive outcomes, and subsequently place a bet based on their confidence in that decision. The involvement of the orbitofrontal cortex - and the anterior cingulate cortex - in performance on the Risk Task (an adaptation of the RCGT for use in functional imaging) was demonstrated in a positron emission tomography (PET) study (Rogers et al, 1999b). The only RCGT study demonstrated decision-making deficits in both individuals on amphetamines and dependent on heroin, compared with controls (Rogers et al, 1999a).

The Iowa Gambling Task was developed to assess decision-making in patients with ventromedial lesions. The task's essential feature is that it mimics real-life situations in the way that it factors uncertainty, reward and punishment (Bechara et al, 1994, 2000) and emphasises the contribution of emotional processing to decision-making. To earn 'pretend' money, participants need to learn the associations between reward and punishment of four card decks. In all ten IGT studies, participants with substance use disorders performed worse than the controls. The 
Table I Main results from studies using behavioural decision-making tasks

\begin{tabular}{|c|c|c|c|c|c|}
\hline Study & Substance misuse sample & Control group & Abstinence & Method & $\begin{array}{l}\text { Decision-making } \\
\text { deficits }\end{array}$ \\
\hline Petry et al (1998) & $\begin{array}{l}\text { Heroin (out-patients: } 18 \text { men, } \\
14 \text { women) }\end{array}$ & 33 men, 26 women & $\begin{array}{l}\text { Buprenorphine } \\
\text { maintenance }\end{array}$ & IGT & Yes \\
\hline Rogers et al (1999a) & $\begin{array}{l}\text { Amphetamines (14 men, } 4 \text { women) } \\
\text { Opiates (13 men) }\end{array}$ & 16 men, 10 women & $12 \mathrm{~h}$ & RCGT & Yes \\
\hline Grant et al (2000) & Polydrug misuse ( 27 men, 3 women) & 18 men, 4 women & $36-38 \mathrm{~h}$ & IGT & Yes \\
\hline Mazas et al (2000) & $\begin{array}{l}\text { Early-onset alcoholism (I5 men, } \\
12 \text { women) }\end{array}$ & $\begin{array}{l}\text { Control group } \\
\text { (14 men, } 18 \text { women) } \\
\text { ASP group ( } 6 \text { men, } \\
2 \text { women) }\end{array}$ & Sober at testing & IGT & Yes \\
\hline Bechara et al (200 I) & $\begin{array}{l}\text { Substance dependency ( } 21 \text { men, } \\
20 \text { women) }\end{array}$ & 20 men, 20 women & $>15$ days & IGT & Yes \\
\hline Petry (200I) & Substance use disorder (63 men) & 21 men & 0 day & IGT & Yes \\
\hline Bechara \& Damasio (2002) & $\begin{array}{l}\text { Substance dependency ( } 21 \text { men, } \\
25 \text { women) }\end{array}$ & 21 men, 28 women & $>15$ days & IGT+SCR & Yes \\
\hline Bechara et al (2002) & VMPFC lesions ( 5 men, 5 women) & & & $\begin{array}{c}\text { Variant version } \\
\text { IGT+SCR }\end{array}$ & Yes \\
\hline Mintzer \& Stitzer (2002) & $\begin{array}{l}\text { Opioid-dependent MMT (7 men, } \\
\text { II women) }\end{array}$ & 10 men, II women & $24 \mathrm{~h} M M T$ & IGT & Yes \\
\hline Ernst et al (2003) & Same group as in Grant et al (2000) & & & IGT & Yes \\
\hline $\begin{array}{l}\text { Rotheram-Fuller et al } \\
(2004)\end{array}$ & $\begin{array}{l}\text { MMT+tobacco smokers (9) } \\
\text { MMT non-smokers (9) }\end{array}$ & $\begin{array}{l}\text { Smokers (9) } \\
\text { Non-smokers (10) }\end{array}$ & MMT & IGT & Yes \\
\hline
\end{tabular}

ASP, antisocial personality disorder; IGT, lowa Gambling Task; MMT, methadone maintenance therapy; RCGT, Rogers Cambridge Gamble Task; SCR, skin conductance response; VMPFC, ventromedial prefrontal cortex.

studies that also included patients with ventromedial lesions showed that, compared with the control groups, a higher proportion of the participants with substance use disorders performed within the range of the patients with lesions (Rogers et al, 1999a; Bechara \& Damasio, 2002; Bechara et al, 2001, 2002). Taken together, the studies consistently demonstrate impaired decision-making in patients with substance use disorders relative to controls.

\section{Neuroimaging studies}

Imaging studies during decision-making

The studies using functional imaging during decision-making are summarised in Table

2. Fundamental to this review is the (only)
PET study during IGT and a neutral control task (Bolla et al, 2003). Performance on the IGT within both a group of cocaine users and a control group was positively correlated with activation in the right medial orbitofrontal cortex region. Between-group comparison showed greater metabolic activity of this region during the IGT in the cocaine user group. This may reflect

Table 2 Functional imaging during decision-making tasks

\begin{tabular}{|c|c|c|c|c|c|c|c|}
\hline Study & $\begin{array}{l}\text { Main substance of } \\
\text { misuse (sample) }\end{array}$ & Treatment & $\begin{array}{l}\text { Control } \\
\text { group }\end{array}$ & Abstinence & Method & $\begin{array}{c}\text { OFC } \\
\text { activation }\end{array}$ & Other regions activated \\
\hline Paulus et al (2002) & $\begin{array}{l}\text { Methamphetamine } \\
\text { (10 men })^{\prime}\end{array}$ & In-patient & 10 men & 22.4 days & $\begin{array}{l}\text { TCPT, } \\
\text { TCRT+fMRI }\end{array}$ & Yes & $\begin{array}{l}\text { Sample group showed less task-related } \\
\text { activity in the VMPFC and right OFC } \\
\text { region }\end{array}$ \\
\hline Bolla et al (2003) & $\begin{array}{l}\text { Cocaine ( } 10 \text { men, } \\
3 \text { women) }\end{array}$ & & $\begin{array}{l}10 \text { men, } \\
3 \text { women }\end{array}$ & 25 days & $\begin{array}{l}\text { PET (FDG) } \\
\text { during IGT }\end{array}$ & Yes & $\begin{array}{l}\text { Larger activation in the right OFC and less } \\
\text { in the DLPFC in the cocaine group } \\
\text { Performance on the IGT correlated with } \\
\text { activation of right medial OFC }\end{array}$ \\
\hline Paulus et al (2003) & $\begin{array}{l}\text { Methamphetamine } \\
\text { (14 men) }\end{array}$ & In-patient & $\begin{array}{l}10 \text { men, } \\
4 \text { women }\end{array}$ & 25 days & $\begin{array}{c}\text { TCPT, } \\
\text { TCRT+fMRI }\end{array}$ & Yes & $\begin{array}{l}\text { Methamphetamine-dependent patients } \\
\text { showed less task-related activation in the } \\
\text { OFC (BA 10), DLPFC (BA 9), ACC (BA 32) } \\
\text { and parietal cortex (BA 7) }\end{array}$ \\
\hline
\end{tabular}

ACC, anterior cingulate cortex; BA, Brodmann area; DLPFC, dorsolateral prefrontal cortex; FDG, fluorodeoxyglucose; fMRI, functional magnetic resonance imaging; IGT, lowa Gambling Task; OFC, orbitofrontal cortex; PET, positron emission tomography; TCPT, two-choice prediction task; TCRT, two-choice response task; VMPFC, ventromedial prefrontal cortex.

I. Methamphetamine dependency. 
an effort to compensate for the intrinsically weaker performance of the orbitofrontal cortex in the cocaine group or an effort to compensate for weaker performance of other regions involved in decision-making, such as the dorsolateral prefrontal cortex. Although the cocaine user group's performance on the IGT was inferior to that of the controls, the difference was not significant, possibly owing to the small sample size.

In a functional magnetic resonance imaging (fMRI) study, Paulus et al (2002, 2003) used an experimental decisionmaking task, a two-choice prediction task, in which participation did not know a priori which action was associated with the best outcome, and a neutral control task (two-choice response task). Compared with controls, participants dependent on methamphetamine showed less task-related activation in the orbitofrontal cortex (Brodmann areas (BA) 10 and 11), the dorsolateral prefrontal cortex (BA 9) and the anterior cingulate cortex (BA 32) during the prediction task relative to the response task. This suggests a dysfunction of the orbitofrontal cortex, which is elicited primarily in choices associated with uncertain outcomes.

\section{Imaging studies of cue reactivity}

Twenty neuroimaging studies used a cue exposure or drug priming paradigm to evoke cue reactivity. The findings, ordered by substance, are presented in Table 3 . The results are conflicting. Thirteen studies demonstrated activation of the orbitofrontal cortex in response to cue exposure ('cue reactivity'), whereas six did not. However, several other areas were activated: the dorsolateral prefrontal cortex, amygdala, insular cortices, anterior cingulate cortex and cerebellum. One study showed cue reactivity of the orbitofrontal cortex in male patients addicted to cocaine but not in similarly addicted female patients (Kilts et al, 2004). Seventeen studies included craving measures: two of these studies reported no craving after exposure, whereas six reported an association between the intensity of drug craving or drug 'high' and orbitofrontal cortex activation. In the remaining nine studies craving was associated with other regions.

Priming dose effects ('drug probing'). Six studies measured the effect of placebo and a single dose of the drug of preference (or a closely related drug; Stapleton et al, 1995; Volkow et al, 1996, 1999a, 2003a; Sell et al, 2000; Adinoff et al, 2001). All but one (Adinoff et al, 2003a) demonstrated orbitofrontal cortex activation in response to drug administration. In addition, all but two (Volkow et al, 1996, 2003a) showed orbitofrontal cortex activation to be related to the subjective experience of craving.

Cue exposure during early abstinence. Fourteen studies used a cue exposure paradigm during early abstinence (1-28 days), with the exception of the study by Daglish et al (2001) in which abstinence varied strongly.

Of the seven PET studies, four demonstrated activation of the orbitofrontal cortex in response to cue exposure (Grant et al, 1996; Wang et al, 1999; Daglish et al, 2001; Bonson et al, 2002), whereas two did not (Childress et al, 1999; Kilts et $a l, 2001)$. One PET study demonstrated less activation of this region in female compared with male cocaine-addicted patients (Kilts et al, 2004). Remarkably, all studies focusing on female patients with substance use disorders failed to demonstrate orbitofrontal cortex activation in response to cue exposure (Kilts et al, 2004; Tapert et $a l, 2004$ ) or drug administration (Adinoff et al, 2003a). This suggests gender differences in the functionality of this region and in the degree of its involvement in addictive processes.

Of the seven fMRI studies, three demonstrated involvement of the orbitofrontal cortex in cue reactivity (Garavan et al, 2000; Tapert et al, 2003; Myrick et al, 2004). The between-study inconsistencies may be due to technical limitations. In fMRI designs the investigation of the orbitofrontal cortex can be complicated by susceptibility to artefacts induced by the air-tissue interface (London et al, 2000). Alternatively, differences in cue exposure paradigms may influence results. Using cocaine-related videotapes as cues, Wexler $e t$ al (2001) found higher activity in the anterior cingulate cortex of cocaine-dependent patients, both before these patients experienced any craving and in the absence of craving. George et al (2001), using a sip of alcohol and images of alcoholic beverages, demonstrated thalamic involvement. In another study using videotapes, cocaine craving was associated with the activation of 13 brain areas including the orbitofrontal and anterior cingulate cortices (Garavan et al, 2000). In a PET study using videotaped cues, Kilts et al (2001) demonstrated cue reactivity in the anterior cingulate cortex, right inferior parietal cortex and caudate/lateral dorsal nucleus. Although the activation of these multiple brain areas may imply that craving relates to several neuroanatomical circuits, one might - in line with Kilts et al (2001) - argue that inductive cues such as videotapes are too crude to allow a distinction between activations due to conditioned drug craving and activations associated with accompanying features of psychophysiological arousal, anticipation, memory retrieval, attention and behavioural planning.

Finally, treatment status might influence results. In all but one of the cue exposure studies (Kilts et al 2004) comparing gender differences in patients treated for cocaine addiction) in-patients systematically failed to demonstrate orbitofrontal cortex activation in response to cue exposure, whereas substance misusers responded with activation. The only exception was the study by George et al (2001); however, only 'mildly severe' cases of alcoholism were included, which might account for the lack of orbitofrontal cortex involvement in this study.

In summary, these imaging studies evidence activation of multiple brain regions during cue exposure. The type of drug did not differentially affect orbitofrontal cortex activity. Neither cue reactivity nor craving was exclusively or reliably linked to activation of this brain region. Other regions most frequently associated with cue exposure in patients with substance use disorders are the anterior cingulate cortex, dorsolateral prefrontal cortex and amygdala.

\section{'Brain at rest' imaging studies}

Of the 18 available studies testing the orbitofrontal cortex in drug-dependent patients with the brain 'at rest', only 3 failed to demonstrate involvement of this region. The studies can be divided into 13 metabolic and 5 structural studies (Table 4).

Metabolicstudies. During early withdrawal (less than 7 days of abstinence), the orbitofrontal cortex metabolism in participants with substance use disorders was either comparable with controls (Volkow et al, 1998) or higher than in the control group (Volkow et al, 1991; London et al, 2004). Studies during late withdrawal ( $>7$ days) or prolonged abstinence demonstrated systematically low activity in the orbitofrontal 


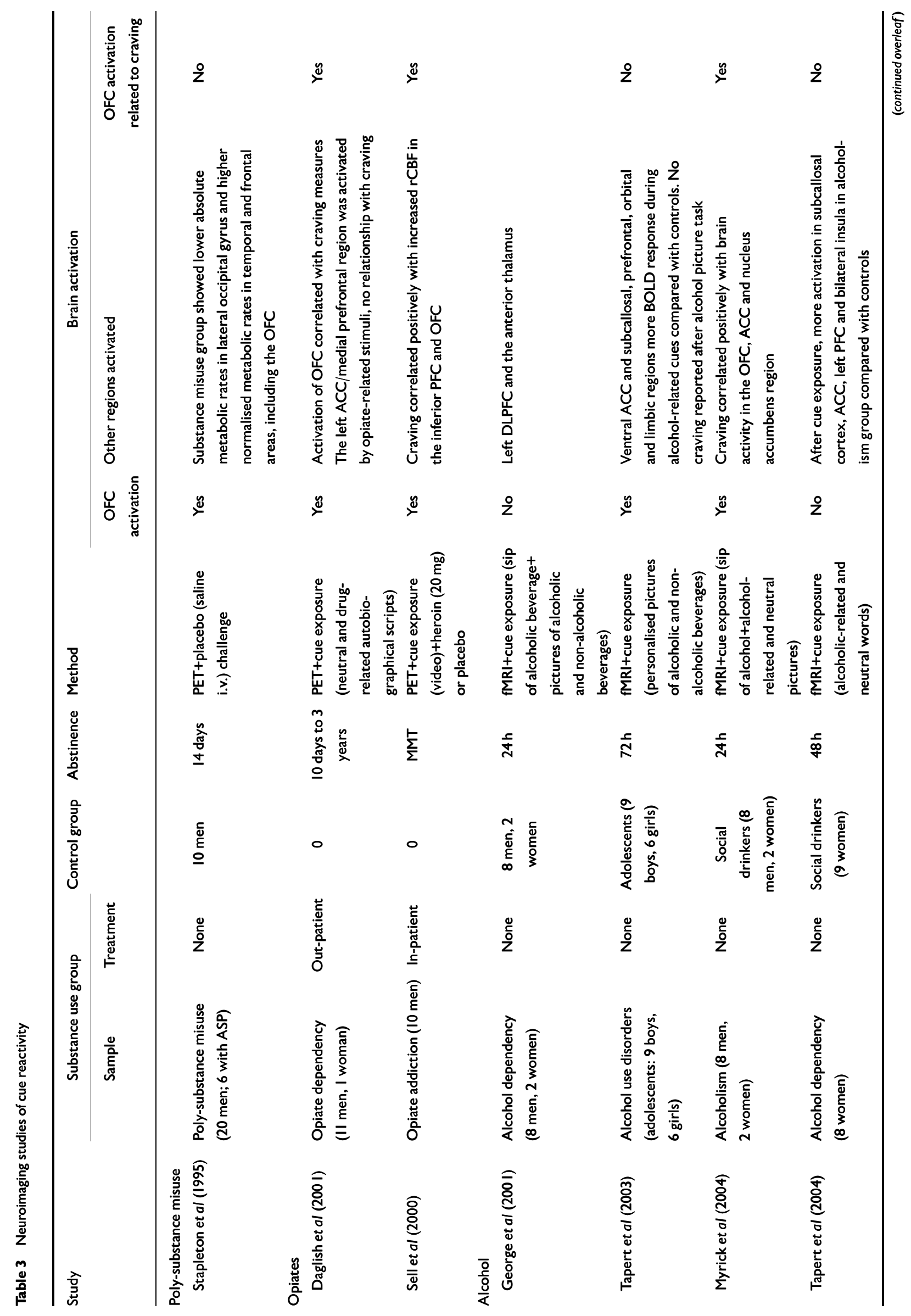




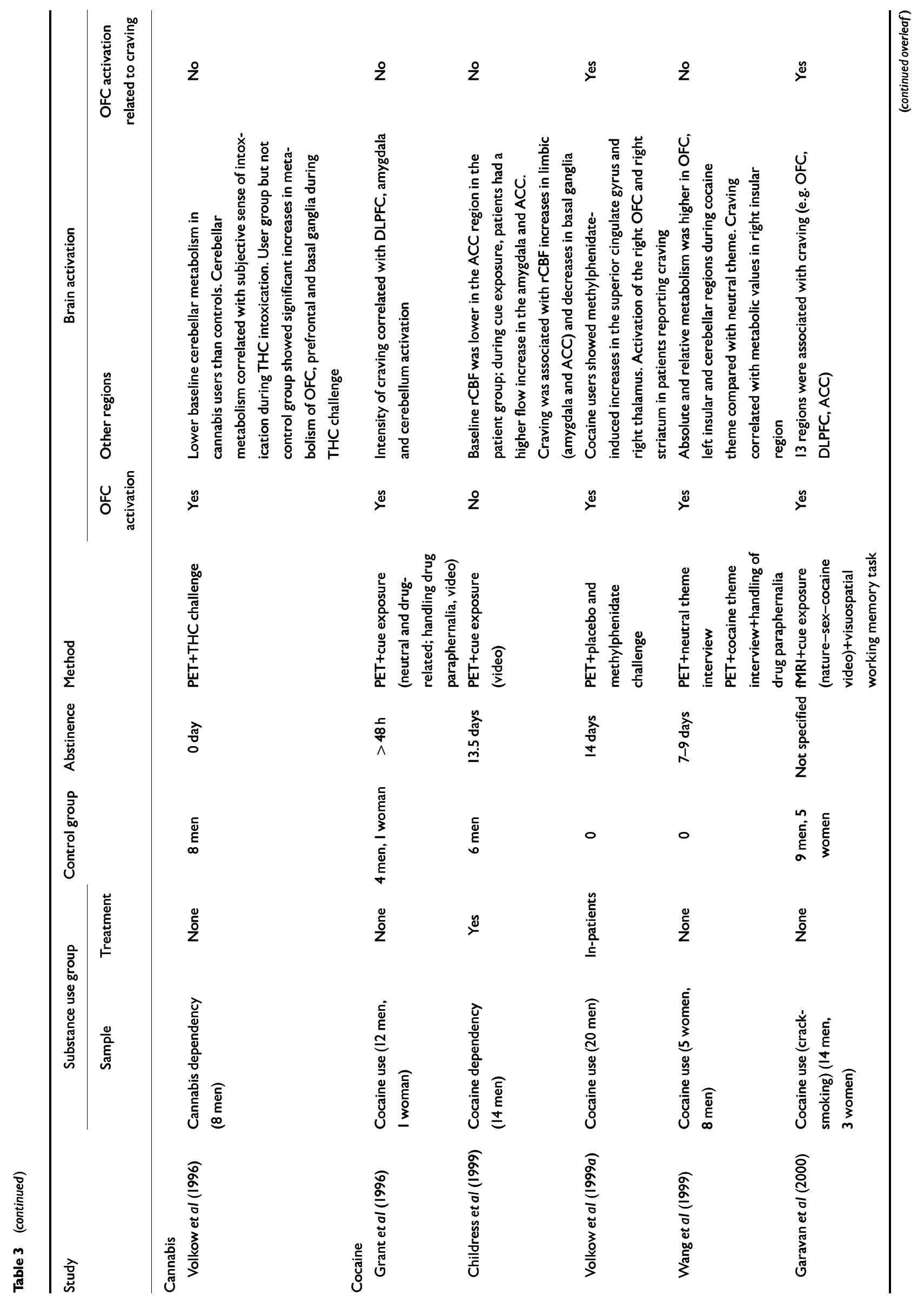




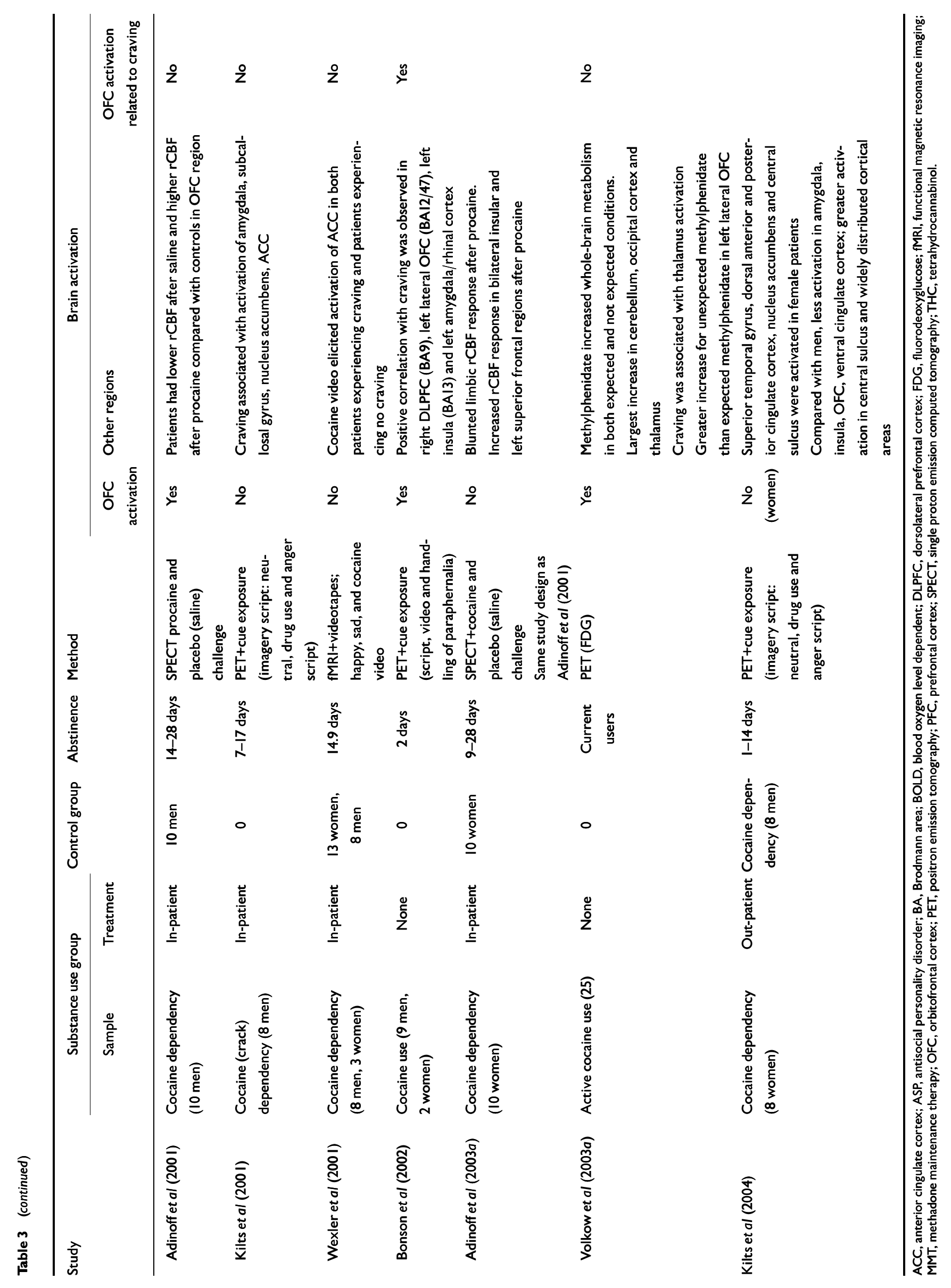




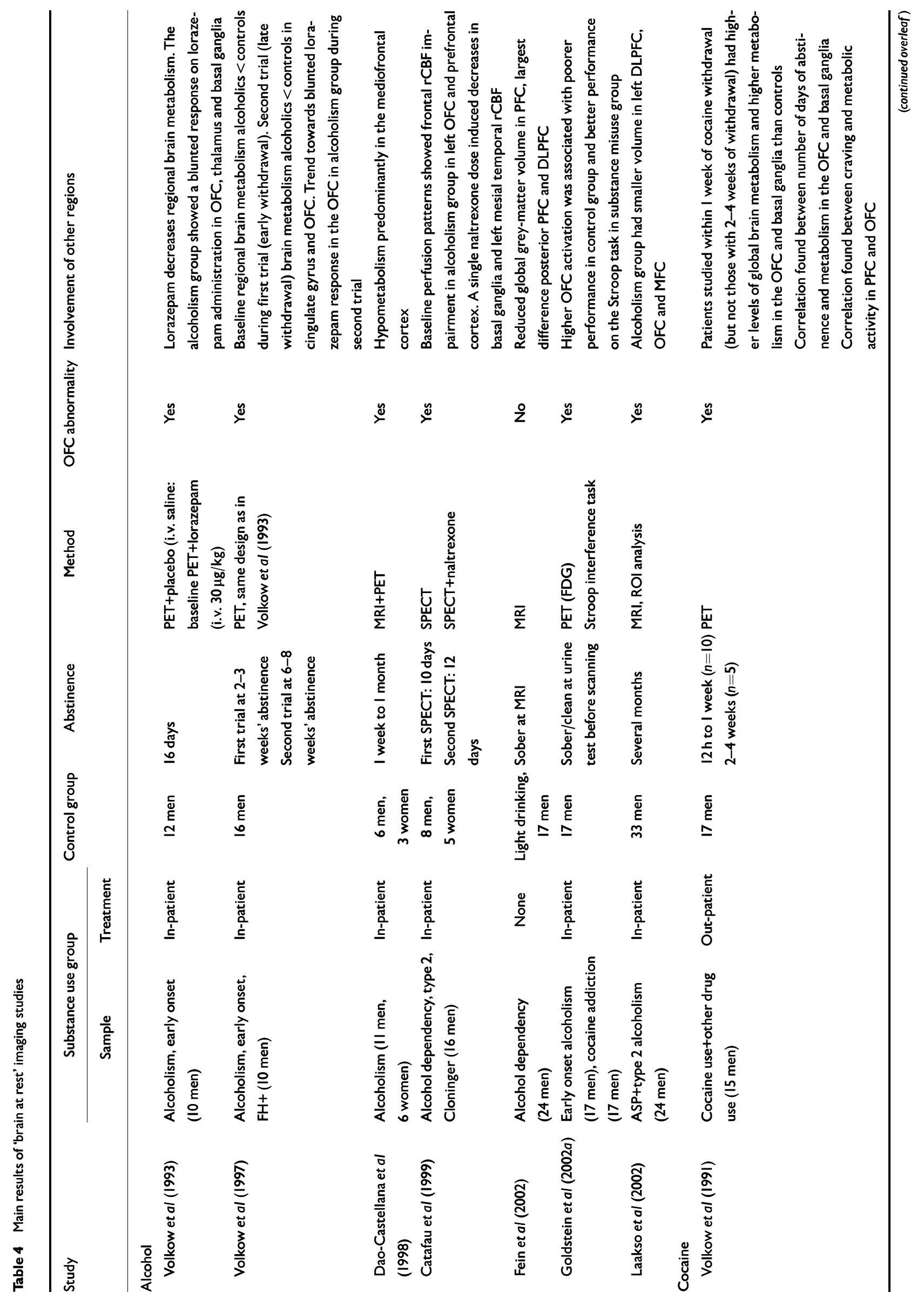




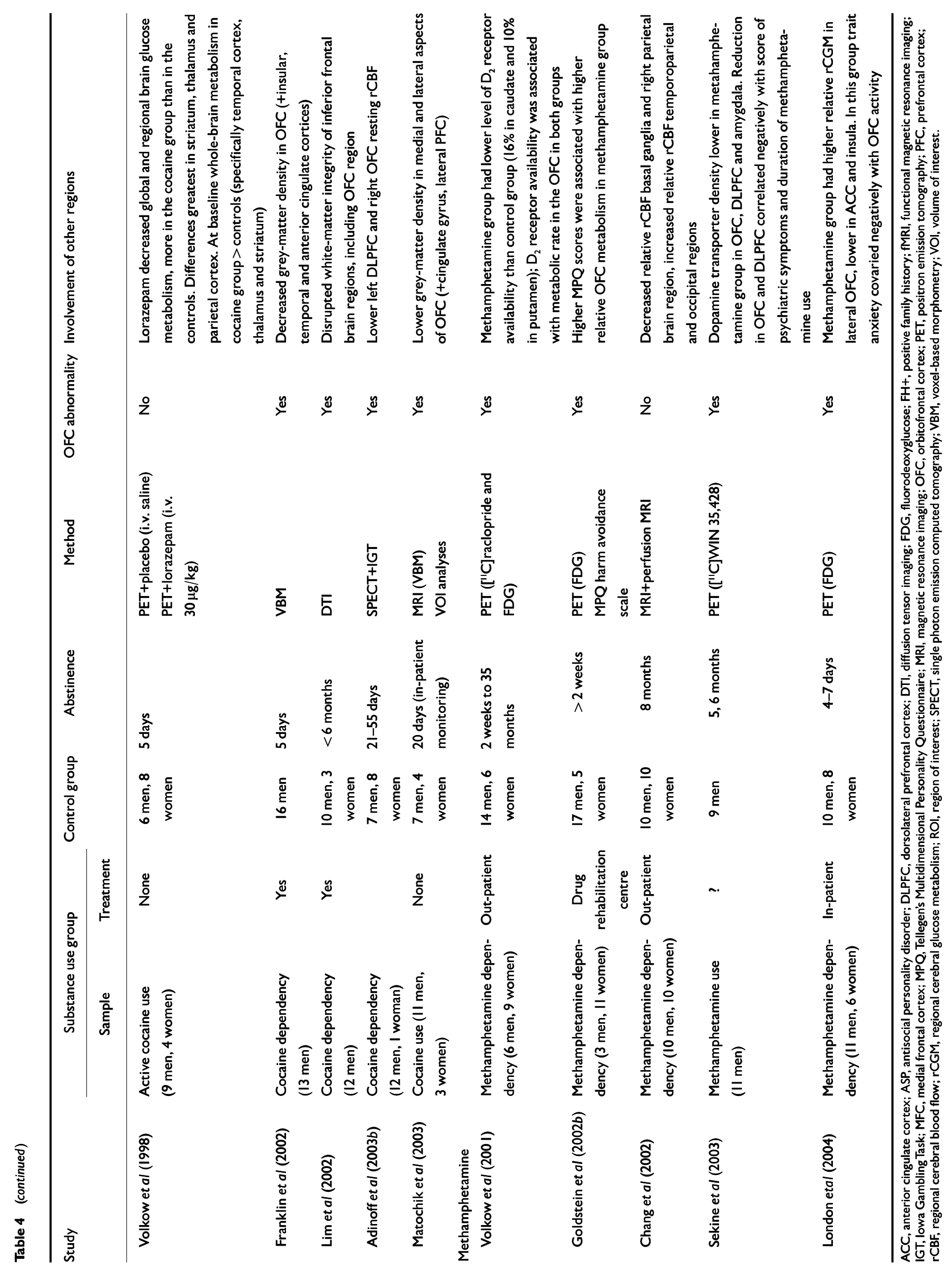


cortex region (Dao-Castellana et al, 1998; Catafau et al, 1999; Volkow et al, 2001; Adinoff et al, 2003b; Sekine et al, 2003; London et al, 2004). Although the studies using a lorazepam challenge do not strictly qualify as 'brain at rest', they all demonstrate hypofunctionality of this brain region after withdrawal (Volkow et al, 1993, 1997, 1998). One study administering the Iowa Gambling Task after PET recording (Adinoff et al, 2003b) showed performance on this task to be positively correlated with dorsolateral prefrontal cortex and anterior cingulate cortex metabolism at rest. All studies of substance use disorder that included measures of psychiatric symptoms or psychological traits indicated involvement of the orbitofrontal cortex in anxiety and disordered mood (Goldstein et al, 2002a,b; Sekine et al, 2003; London et al, 2004).

Only one study, using perfusion magnetic resonance imaging, failed to demonstrate any difference in the orbitofrontal cortex in long-abstinent people with methamphetamine dependency relative to a normal control group (Chang et al, 2002). This may reflect brain recovery. Recently, Wang et al (2004) demonstrated partial recovery of brain function after longlasting abstinence in methamphetaminedependent patients.

Structural studies. Three studies revealed smaller volumes (Laakso et al, 2002) and decreased grey-matter density in the orbitofrontal cortex (Franklin et al, 2002; Matochick et al, 2003). Another study showed disruption in white-matter integrity, predominantly in the inferior frontal brain regions, indicative of disrupted connectivity in the orbitofrontal cortex region (Lim et $a l, 2002$ ). One study (Fein et al, 2002) did not report orbitofrontal cortex abnormalities but did demonstrate reduced global prefrontal grey-matter volume in treatmentnaïve heavy drinkers without severe behavioural consequences of their alcohol use.

Taken together, the structural and metabolic studies demonstrate involvement of the orbitofrontal cortex in people with addictions. The main findings concerning this region are its hyperactivation during early withdrawal, hypoactivation after withdrawal or during prolonged abstinence, and its involvement in mood and anxiety changes in patients with substance use disorders.

\section{DISCUSSION}

Fifty-two studies were evaluated. Behavioural decision-making tasks consistently demonstrate impairments in decisionmaking in patients with substance use disorders compared with controls. In contrast, the relationship between orbitofrontal cortex activity, cue reactivity and craving is not consistent across the studies reviewed. Studies during acute withdrawal reveal hyperactivation of the orbitofrontal cortex, whereas studies during abstinence demonstrate hypoactivation of this region and structural abnormalities in individuals with substance use disorders.

\section{Decision-making and the orbitofrontal cortex}

The results obtained with the behavioural decision-making tasks warrant further elucidation. First, it remains uncertain whether the different tasks all measure the same cognitive entity. An overlap in the decision-making functions tapped by the IGT and the RCGT has been demonstrated (Monterosso et al, 2001). However, no data are available comparing the twochoice prediction task (Paulus et al, 2002, 2003) with the IGT and the RCGT. Second, studies analysing the relationship between behavioural decision-making tasks and the orbitofrontal cortex as their anatomical correlate are limited and conflicting. The sole neuroimaging study during IGT performance showed a task-related increase in orbitofrontal cortex metabolism in the cocaine users group (Bolla et al, 2003). In contrast, studies using the two-choice prediction task found decreases in task-related activity in the right orbitofrontal cortex and the anterior cingulate cortex of methamphetamine-dependent participants (Paulus et al, 2002, 2003). This inconsistency may reflect intrinsic differences between these decision-making tasks. Anatomically, both the orbitofrontal and the anterior cingulate cortex are involved in all three decision-making tasks. As to the IGT, which is a complex task depending on a variety of cognitive processes, other regions seem to contribute as well (i.e. the dorsolateral prefrontal cortex, amygdala and insular regions; Clark et al, 2003).

Taken together, as discussed by Lubman et al (2004), the orbitofrontal and anterior cingulate cortices are critically involved in inhibitory decision-making processes, especially involving reward-related behaviours (Elliott et al, 2000; Kiehl et al, 2000; Fan et al, 2003; Rogers et al, 2004). Specifically, these regions process the reward value and/or affective valence of environmental stimuli, assess the future consequences of the individual's own actions (response selection) and inhibit inappropriate behaviours (response inhibition; Elliott et al, 2000; Kiehl et al, 2000; Bechara \& Damasio, 2002; Krawczyk, 2002; Fan et al, 2003). Dysfunctions within these regions have recently been proposed as a key neural mechanism underlying addiction (Jentsch \& Taylor, 1999; Goldstein \& Volkow, 2002; Volkow et al, 2003b; Lubman et al, 2004).

\section{The orbitofrontal cortex, cue reactivity and craving}

Findings concerning the relationship between the orbitofrontal cortex, cue reactivity and craving are inconsistent across the studies. Of 20 studies, 13 demonstrated cue exposure to be associated with hyperactivity of the orbitofrontal cortex. One study demonstrated cue-induced hyperactivity in male patients with cocaine addiction but not in female patients. In addition, other brain regions are involved as well: the amygdala, dorsolateral prefrontal cortex and anterior cingulate cortex were the most commonly reported loci of activation.

The inconsistencies between the various studies may originate from differences in study design, drug use status, treatment status or gender. First, different cue exposure paradigms have been used. As yet, not enough is known about the effects elicited by the different types of non-chemical cues (videotapes, drug paraphernalia, script reading) and chemical cues (single dose administration, ethanol odour). Possibly, different cues affect different brain circuits. Second, drug use status seems important. Withdrawal is consistently linked with orbitofrontal cortex activation. In addition, single drug-dose administration (drug probing) systematically evokes hyperactivity of this region; this is of high clinical relevance, since it is known that during abstinence the use of a limited amount of the drug of choice is a powerful trigger of craving and reinstatement of drug-taking habits in people with addictions. Third, treatment status may relate to cue reactivity. Wilson et al (2004) proposed the treatment-seeking state of the participants as a variable explaining the disparity in brain-region activation in response to cue exposure. 
Non-treatment-seeking people with addictions could anticipate more actual drug use shortly after testing than those who were treatment-seeking. The studies on cue exposure in the current review lend some support to this hypothesis. Finally, gender differences might mediate differences in orbitofrontal cortex cue reactivity. In the three studies of women with substance use disorders, cue exposure elicited no activity in this brain region; this suggests that processing of reward/salience may involve different neural circuits in men and women. Noteworthy in this respect is that, increasingly, research is revealing gender differences in IGT performance, with men performing better than women (Reavis \& Overman, 2001; Bolla et al, 2004; Overman, 2004).

The relationship between orbitofrontal cortex activity and experiences of craving remains unclear. Craving is a complex process that may involve several interacting brain regions (for a review, see Franken, 2003). Craving is associated with the learned response that links the drug and its environment to an intensely pleasurable experience. Anatomically, the consolidation of this memory (trait craving) is likely to involve the amygdala, hippocampus and the nucleus accumbens shell. The actual conscious experience of craving as a result of cue reactivity has been postulated to be linked to the orbitofrontal cortex and possibly the anterior cingulate cortex (Goldstein \& Volkow, 2002). However, in our review the data did not conclusively support this hypothesis. In only 6 of the 17 studies $(35 \%)$ was craving associated with orbitofrontal cortex activation. In 9 other studies other brain regions were implicated. Further research is warranted to differentiate the roles of the orbitofrontal and anterior cingulate cortices and other regions involved in cue reactivity and craving.

\section{Orbitofrontal cortex activity after withdrawal}

The structural and metabolic neuroimaging studies after drug withdrawal consistently demonstrated a decrease in orbitofrontal cortical volume, metabolism and functionality. These findings are in line with other reports revealing reductions in dopamine $\mathrm{D}_{2}$ receptor density in people with substance use disorders (Volkow et al, 1999b, 2001). Among other regions, the areas affected are the dopaminergic projections from the striatum (nucleus accumbens) to the cingulate gyrus, prefrontal cortex and the orbitofrontal cortex. This deficit may play an important part in addictive processes, conceptualised as a process of hedonic homoeostatic dysregulation (Koob \& Le Moal, 1997). Clinical correlates of a hedonic dysregulation are the dysthymic or depressive episodes that are frequently observed after detoxification. These mood changes can be persistent and difficult to treat. Such an anhedonic state can be a serious hazard in maintaining abstinence and may induce a relapse. The studies by London et al (2004), Sekine et al (2003), and Goldstein et al (2002b) suggest involvement of the orbitofrontal cortex in mood and anxiety disorders in methamphetamine addiction.

\section{General remarks}

In addition to their drug of preference, many participants in the studies we reviewed used (and misused) multiple other substances. Although poly-substance misuse is of particular clinical interest, becoming a common pattern of drug misuse, it complicates the interpretation of the results. Furthermore, although most of the participants with substance use disorders were nicotine-dependent, nicotine status was never taken into account in the various studies. This might also have biased the results reported, since nicotine use itself has been linked to changes in orbitofrontal and anterior cingulate cortical metabolism (Brody et al, 2002). Future studies should take into account this potential confounding factor, either by excluding smokers or by statistical adjustment for smoking status.

Finally, the findings in the studies under review do not allow a distinction to be made between cause and consequence. Functional and structural deficits in decision-making cognition and orbitofrontal cortex integrity can be either a consequence of or a pre-existent vulnerability to addictive behaviour. For some drugs of misuse such as methamphetamine, evidence of their (sometimes long-lasting) neurotoxic effects is growing (Wang et al, 2004). However, the findings reported on in this review seem to be relatively independent of the type of substance misused. The observed abnormalities are probably not substancespecific but rather constitute a common deficit in addicted states and/or a common predisposing vulnerability (Blum et al, 2000). In this context, it might be of interest to mention the evidence demonstrating involvement of the orbitofrontal cortex in non-chemical addictions such as gambling (Cavedini et al, 2002; Potenza et al, 2003; Goudriaan et al, 2004).

Collectively, both the behavioural and neuroimaging studies included in this review point to an important role of the orbitofrontal cortex in addictive processes. They lend further support for the model developed by Volkow et al $(2003 b, 2004)$, who propose a network of four brain circuits involved in addiction (memory, drive, reward and control). In this model, exposure to the drug or to drug-related cues activates the memory of the expected reward, resulting in hyperactivation of the reward and motivational circuits while decreasing the activity in the cognitive control system. The deficits highlighted in our review are indicative of an important role for the orbitofrontal cortex in a brain circuit mediating goal-directed behaviour, leading to compulsive drug-seeking and relapse. In doing so, the orbitofrontal cortex contributes to the perpetuation of the addiction.

\section{ACKNOWLEDGEMENT}

The authors thank Eric Achten, MD, PhD, of the Workgroup fMRI Ghent, University of Ghent, Belgium, for his assistance in analysing the neuroimaging studies.

\section{REFERENCES}

Adinoff, B., Devous, M., Best, S., et al (200I) Limbic responsiveness to procaine in cocaine-addicted subjects. American Journal of Psychiatry, I58, 390-398.

Adinoff, B., Devous, M. D., Best, S. E., et al (2003a) Regional cerebral blood flow in female cocaine-addicted subjects following limbic activation. Drug and Alcohol Dependence, 7I, 255-268.

Adinoff, B., Devous, M. D., Cooper, D. B., et al (2003b) Resting regional cerebral blood flow and gambling task performance in cocaine-dependent subjects and healthy comparison subjects. American journal of Psychiatry, 160, 1892-1894.

Bechara, A. \& Damasio, H. (2002) Decision-making and addiction (part I): impaired activation of the somatic states in substance dependent individuals when pondering decisions with negative future consequences. Neuropsychologia, 40, 1675-1689.

Bechara, A., Damasio, A. R., Damasio, H., et al (1994) Insensitivity to future consequences following damage to human prefrontal cortex. Cognition, 50, 7-15.

Bechara, A., Damasio, H. \& Damasio, A. R. (2000) Emotion, decision making and the orbitofrontal cortex. Cerebral Cortex, 10, 295-307.

Bechara, A., Dolan, S., Denberg, N., et al (200I)

Decision-making deficits, linked to a dysfunctional ventromedial prefrontal cortex, revealed in alcohol and stimulant abusers. Neuropsychologia, 39, 376-389. 
Bechara, A., Dolan, S. \& Hindes, A. (2002) Decisionmaking and addiction (part 2): myopia for the future or hypersensitivity to reward? Neuropsychologia, 39, 1690-1705.

Blum, K., Braverman, E. R., Holder, J. M., et al (2000) Reward deficiency syndrome: a biogenetic model for the diagnosis and treatment of impulsive, addictive, and compulsive behaviors. Journal of Psychoactive Drugs, 32 (suppl. I-4), I-112.

Bolla, K. I., Eldreth, D. A., London, E. D., et al (2003) Orbitofrontal cortex dysfunction in abstinent cocaine abusers performing a decision-making task. Neurolmage, 19, 1085-1094.

Bolla, K. I., Eldreth, D. A., Matochik, J. A., et al (2004) Sex-differences in a gambling task and its neurological correlates. Cerebral Cortex, 14, 1226-1232.

Bonson, K. R., Grant, S. J., Contoreggi, C. S., et al (2002) Neural systems and cue-induced cocaine craving. Neuropsychopharmacology, 26, 376-386.

Brody, A. L., Mandelkern, M. A., London, E. D., et al (2002) Brain metabolic changes during cigarette craving. Archives of General Psychiatry, 59, 1162-1172.

Catafau, A. M., Etcheberrigaray, A., Perez de los Cobos, J., et al (1999) Regional cerebral blood flow changes in chronic alcoholic patients induced by naltrexone challenge during detoxification. Journal of Nuclear Medicine, 40, 19-24.

Cavedini, P., Riboldi, G., Keller, R., et al (2002) Frontal lobe dysfunction in pathological gambling patients. Biological Psychiatry, 5I, 334-35I.

Chang, L., Ernst, T., Speck, O., et al (2002) Perfusion MRI and computerized cognitive test abnormalities in abstinent methamphetamine users. Psychiatry Research Neuroimaging, II4, 65-79.

Childress, A. R., Mozley, P. D., McElgin, W. B. A., et al (1999) Limbic activation during cue-induced cocaine craving. American Journal of Psychiatry, I56, $11-18$

Clark, L., Manes, F., Antoun, N., et al (2003) The contributions of lesion laterality and lesion volume to decision-making impairment following frontal lobe damage. Neuropsychologia, 4I, 1474-1483.

Daglish, M. R., Weinstein, A., Malizia, A. L., et al (200I) Changes in regional cerebral blood flow elicited by craving memories in abstinent opiatedependent subjects. American Journal of Psychiatry, 158 1680-1686.

Dao-Castellana, M. H., Samson, Y., Legault, F., et al (1998) Frontal dysfunction in neurologically normal chronic alcoholic subjects: metabolic and neuropsychological findings. Psychological Medicine, $\mathbf{2 8}$ 1039-1048.

Elliott, R., Friston, K. J. \& Dolan, R. J. (2000)

Dissociable neural responses in human reward systems. Journal of Neuroscience, 20, 6159-6165.

Ernst, M., Grant, S. J., London, E. D., et al (2003) Decision making in adolescents with behavioural disorders and adults with substance abuse. American Journal of Psychiatry, 160, 33-40.

Fan, J., Flombaum, J. I., McCandliss, B. D., et al (2003) Cognitive and brain consequences of conflict. Neurolmage, 18, 42-57.

Fein, G., Di Sclafani, V., Cardenas, A., et al (2002) Cortical gray matter loss in treatment-naive alcohol dependent individuals. Alcoholism: Clinical and Experimental Research, 26, 558-564.

Franken, I. H. (2003) Drug craving and addiction: integrating psychological and neuropsychopharmaco- logical approaches. Progress in Neuropsychopharmacology and Biological Psychiatry, 27, 563-579.

Franklin, T. R., Acton, P. D., Maldjian, J. A., et (2002) Decreased gray matter concentration in the insular, orbitofrontal, cingulate, and temporal cortices of cocaine patients. Biological Psychiatry, 5I, 134-142.

Garavan, H., Pankiewicz, J., Bloom, A., et al (2000) Cue-induced cocaine craving: neuroanatomical specificity for drug users and drug stimuli. American Journal of Psychiatry, 157, 1789-1798.

George, M. S., Anton, R. F., Bloomer, C., et al (200I) Activation of prefrontal cortex and anterior thalamus in alcoholic subjects on exposure to alcohol-specific cues. Archives of General Psychiatry, 58, 345-382.

Goldstein, R. Z. \& Volkow, N. D. (2002) Drug addiction and its underlying neurobiological basis: neuroimaging evidence for the involvement of the frontal cortex. American Journal of Psychiatry, 159 1642-1652.

Goldstein, R. Z., Volkow, N. D., Wang, G. J., et al (2002a) Addiction changes orbitofrontal gyrus function: involvement in response inhibition. NeuroReport, $\mathbf{1 2}$, 2595-2500

Goldstein, R. Z., Volkow, N. D., Chang, L., et al (2002b) The orbitofrontal cortex in methamphetamine addiction: involvement in fear. NeuroReport, $\mathbf{1 3}$ 2253-2257.

Goudriaan, A. E., Oosterlaan, J., de Beurs, E., et al (2004) Pathological gambling: a comprehensive review of biobehavioral findings. Neuroscience and Biobehavioral Reviews, 28, |23-|4|.

Grant, S., London, E. D., Newlin, D. B., et al (1996) Activation of memory circuits during cue-elicited cocaine craving. Proceedings of the National Academy of Sciences of the USA, 93, 12040-12045.

Grant, S., Contoreggi, C. \& London, E. D. (2000) Drug abusers show impaired performance in a laboratory test of decision making. Neuropsychologia, 38 1180-1187.

Jentsch, J. D. \& Taylor, J. R. (1999) Impulsivity resulting from frontostriatal dysfunction in drug abuse: implications for the control of behavior by reward related stimuli. Psychopharmacology (Berlin), 146, 373-390.

Kiehl, K. A., Liddle, P. F. \& Hopfinger, J. B. (2000) Error processing and the rostral anterior cingulate: an event-related fMRI study. Psychophysiology, 37, 216-223.

Kilts, C. D., Schweitzer, J. B., Quinn, C. K., et al (200I) Neural activity related to drug craving in cocaine addiction. Archives of General Psychiatry, 58, $334-341$

Kilts, C. D., Gross, R. E., Ely, T. D., et al (2004) The neural correlates of cue-induced craving in cocainedependent women. American Journal of Psychiatry, 161, 233-241.

Koob, G. F. \& Le Moal, M. (1997) Drug abuse: hedonic homeostatic dysregulation. Science, 278, 52-58.

Krawczyk, D. C. (2002) Contributions of the prefrontal cortex to the neural basis of human decision making. Neuroscience and Biobehavioral Reviews, 26, $631-664$

Laakso, M. P., Gunning-Dixon, F., Vaurio, O., et al (2002) Prefrontal volumes in habitually violent subjects with antisocial personality disorder and type 2 alcoholism. Psychiatry Research Neuroimaging, II4 95-102.

Lim, K. O., Choi, S. J., Pomara, N., et al (2002) Reduced frontal white matter integrity in cocaine dependence: a controlled diffusion tensor imaging study. Biological Psychiatry, 5I, 890-895.

London, E. D., Ernst, M., Grant, S., et al (2000) Orbitofrontal cortex and human drug abuse: functional imaging. Cerebral Cortex, 10, 334-342.

London, E. D., Simon, S. L., Berman, S. M., et al (2004) Mood disturbances and regional cerebral metabolic abnormalities in recently abstinent methamphetamine abusers. Archives of General Psychiatry, 6I, 73-84.

Lubman, D. I., Yucel, M. \& Pantelis, C. (2004) Addiction, a condition of compulsive behaviour? Neuroimaging and neuropsychological evidence of inhibitory dysregulation. Addiction, 999, 149|-1502.

Maas, L. C., Lukas, S. E., Kaufman, M. J., et al (1998) Functional magnetic resonance imaging of human brain activation during cue-induced cocaine craving. American Journal of Psychiatry, 155, 124-126.

Matochik, J. A., London, E. D., Eldreth, D. A., et a (2003) Frontal cortical tissue composition in abstinent cocaine abusers: a magnetic resonance imaging study Neurolmage, 19, 1095-1102.

Mazas, C. A., Finn, P. R. \& Steinmetz, J. E. (2000) Decision-making biases, antisocial personality, and early-onset alcoholism. Alcoholism: Clinical and Experimental Research, 24, 1036-1040.

Mintzer, M. Z. \& Stitzer, M. L. (2002) Cognitive impairment in methadone maintenance patients. Drug and Alcohol Dependence, 67, 4I-5I.

Monterosso, J., Ehrman, R., Napier, K., et al (200I) Three decision-making tasks in cocaine-dependent patients: do they measure the same construct? Addiction, 96, 1825-1837.

Myrick, H., Anton, R. F., Li, X., et al (2004) Differential brain activity in alcoholics and social drinkers to alcohol cues: relationship to craving. Neuropsychopharmacology, 29, 393-402.

Overman, W. H. (2004) Sex differences in early childhood, adolescence, and adulthood on cognitive tasks that rely on orbital prefrontal cortex. Brain and Cognition, 55, 134-147.

Paulus, M. P., Hozack, N. E., Zauscher, B. E., et al (2002) Behavioral and functional neuroimaging evidence for prefrontal dysfunction in methamphetaminedependent subjects. Neuropsychopharmacology, 26. 53-63.

Paulus, M. P., Hozack, N., Frank, L., et al (2003) Decision making by methamphetamine-dependent subjects is associated with error-related-independent decrease in prefrontal and parietal activation. Biological Psychiatry, 53, 65-74.

Petry, N. M. (200I) Substance abuse, pathological gambling, and impulsiveness. Drug and Alcohol Dependence, 63, 29-38.

Petry, N. M., Bickel, W. K. \& Arnett, M. (1998)

Shortened time horizons and insensitivity to future consequences in heroin addicts. Addiction, 93 729-738

Potenza, M. N., Steinberg, M. A., Skudlarski, P., et al (2003) Gambling urges in pathological gambling: a functional magnetic resonance imaging study. Archives of General Psychiatry, 60, 828-836.

Reavis, R. \& Overman, W. H. (200I) Adult sex differences on a decision-making task previously shown to depend on the orbital prefrontal cortex. Behavioral Neuroscience, II5, 196-206.

Rogers, R. D., Everitt, B. J., Baldacchino, A., et al (1999a) Dissociable deficits in the decision-making cognition of chronic amphetamine abusers, opiate 
abusers, patients with focal damage to prefronta cortex, and tryptophan-depleted normal volunteers: evidence for monoaminergic mechanisms. Neuropsychopharmacology, 20, 322-339.

Rogers, R. D., Owen, A. M., Middleton, H. C., et al (1999b) Choosing between small, likely rewards and large, unlikely rewards activates inferior and orbital prefrontal cortex. Journal of Neuroscience, $\mathbf{2 0}$, 9029-9038.

Rogers, R. D., Ramnani, N., Mackay, C., et al (2004) Distinct portions of anterior cingulate cortex and media prefrontal cortex are activated by reward processing in separable phases of decision-making cognition. Biological Psychiatry, 55, 594-602.

Rotheram-Fuller, E., Shoptaw, S., Berman, S. M., et al (2004) Impaired performance in a test of decisionmaking by opiate-dependent tobacco smokers. Drug and Alcohol Dependence, 73, 79-86.

Schneider, F., Habel, U., Wagner, M., et al (200I) Subcortical correlates of craving in recently abstinent alcoholic patients. American Journal of Psychiatry, I58, 1075-1083.

Sekine, Y., Minabe, Y., Ouchi, Y., et al (2003) Association of dopamine transporter loss in the orbitofrontal and dorsolateral prefrontal cortices with methamphetamine-related psychiatric symptoms. American Journal of Psychiatry, 160, 1699-1701.

Sell, L. A., Morris, J. S., Bearn, J., et al (2000) Neura responses associated with cue-evoked emotional states and heroin in opiate addicts. Drug and Alcohol Dependence, 60, 207-216.

Stapleton, J. M., Morgan, M. J., Phillips, R. L., et al (1995) Cerebral glucose utilization in polysubstance abuse. Neuropsychopharmacology, 13, 21-31.

Tapert, S. F., Cheung, E. H., Brown, G. G., et al (2003) Neural response to alcohol stimuli in adolescents with alcohol use disorder. Archives of General Psychiatry, 60, 727-735.

Tapert, S. F., Brown, G. G., Baratta, M.V., et al (2004) fMRI BOLD response to alcohol stimuli in alcohol-dependent young women. Addictive Behaviors, 29. $33-50$.

Volkow, N. D., Fowler, J. S., Wolf, A. P., et al (1991) Changes in brain glucose metabolism in cocaine dependence and withdrawal. American Journal of Psychiatry, 148, 621-626.

Volkow, N. D., Wang, G. J., Hitzemann, R., et al (1993) Decreased cerebral response to inhibitory neurotransmission in alcoholics. American journal of Psychiatry, 150, 417-422.

Volkow, N. D., Wang, G. J., Hitzemann, R., et al (1994) Recovery of brain glucose metabolism in detoxified alcoholics. American Journal of Psychiatry, I5I, 178-183.

Volkow, N. D., Gillespie, H., Mullani, N., et al (1996) Brain glucose metabolism in chronic marijuana users at baseline and during marijuana intoxication. Psychiatry Research, 67, 29-38.

Volkow, N. D., Wang, G. J., Overall, J. E., et al (1997) Regional brain metabolic response to lorazepam in alcoholics during early and late alcohol detoxification. Alcoholism: Clinical and Experimental Research, 2I $1278-1284$

Volkow, N. D., Wang, G. J., Fowler, J. S., et al (1998) Enhanced sensitivity to benzodiazepines in active cocaine-abusing subjects: a PET study. American Journal of Psychiatry, 155, 200-206.

Volkow, N. D., Wang, G. F., Fowler, J. S., et al (1999a) Association of methylphenidate-induced craving with changes in right striato-orbitofrontal metabolism in

\section{CLINICAL IMPLICATIONS}

- Pharmacological and behavioural treatment should allow for the powerful effect drug probing has on hyperactivation of the orbitofrontal cortex and the associated risk of craving and reinstatement of drug use.

- Future research should focus on the aetiological, diagnostic and therapeutic aspects of mood disorders and anhedonic states following withdrawal related to chronic hypofunctionality of this brain region.

- Extensive documentation of treatment status is warranted in future imaging studies on cue reactivity and craving.

\section{LIMITATIONS}

- The lowa Gambling Task is not specific for orbitofrontal cortex functionality. Studies using more specific behavioural tasks should be used in research into substance misuse.

- Our review exclusively highlights the role of the orbitofrontal cortex in decisionmaking. Other behavioural aspects characteristic of addictive processes (e.g. impulse control) related to this region have not been considered.

- Studies specifically focusing on gambling and tobacco-smoking were excluded. Future reviews should take these populations into account.

G. DOM, MD, Psychiatric Centre Brothers Alexians, Boechout, Belgium; B. SABBE, MD, PhD, Collaborative Antwerp Psychiatric Research Institute (CAPRI), University of Antwerp, Belgium; W. HULSTIJN, PhD, Nijmegen Institute for Cognition and Information, Nijmegen, The Netherlands, and CAPRI, University of Antwerp, Belgium; W. VAN DEN BRINK, MD, PhD, Department of Psychiatry, Academic Medical Centre, University of Amsterdam, and Amsterdam Institute for Addiction Research (AIAR), Amsterdam, The Netherlands

Correspondence: Dr G. Dom, Psychiatric Centre Brothers Alexians, Provinciesteenweg 408, 2530 Boechout, Belgium. Tel: +32 3455 7531; e-mail: geert.dom@fracarita.org

(First received 13 September 2004, final revision 24 January 2005, accepted 28 January 2005)

cocaine abusers: implications in addiction. American Journal of Psychiatry, 156, 19-26.

Volkow, N. D., Wang, G. F., Fowler, J. S., et al (1999b) Prediction of reinforcing responses to psychostimulants in humans by brain dopamine D2 receptor levels. American Journal of Psychiatry, 156, 1440-1443.

Volkow, N. D., Chang, L., Wang, G. J., et al (200I) LoW level of brain dopamine D2 receptors in methamphetamine abusers: association with metabolism in the orbitofrontal cortex. American Journal of Psychiatry, 158, 2015-202I.

Volkow, N. D., Wang, G. J., Ma, Y., et al (2003a) Expectation enhances the regional brain metabolic and the reinforcing effects of stimulants in cocaine abusers. Journal of Neuroscience, 23, ||46|-||468.

Volkow, N. D., Fowler, J. S. \& Wang, G. J. (2003b) The addicted human brain: insights from imaging studies. Journal of Clinical Investigation, III, 1444-145I.

Volkow, N. D., Fowler, J. S. \& Wang, G. J. (2004) The addicted human brain viewed in the light of imaging studies: brain circuits and treatment strategies. Neuropharmacology, 47, 3-13.

Wang, G. F., Volkow, N. D., Fowler, J. S., et al (1999) Regional brain metabolic activation during craving elicited by recall of previous drug experiences. Life Sciences, 64, 775-784.

Wang, G. J., Volkow, N. D., Chang, L., et al (2004)

Partial recovery of brain metabolism in

methamphetamine abusers after protracted abstinence. American Journal of Psychiatry, 16I, 193-194.

Wexler, B. E., Gottschalk, C. H., Fulbright, R. K., et a (200I) Functional magnetic resonance imaging of cocaine craving. American Journal of Psychiatry, 158 $86-95$.

Wilson, S. J., Sayette, M. A. \& Fiez, J. A. (2004) Prefrontal responses to drug cues: a neurocognitive analysis. Nature Neuroscience, 7, 211-214.

Wrase, J., Grüsser, S. M., Klein, S., et al (2002) Development of alcohol-associated cues and cueinduced brain activation in alcoholics. European Psychiatry, I7, 287-291. 